\title{
BMJ Open Improving opioid safety practices in primary care: protocol for the development and evaluation of a multifaceted, theory-informed pilot intervention for healthcare providers
}

\author{
Pamela Leece, ${ }^{1}$ Daniel Z Buchman,,${ }^{1,2,3}$ Michael Hamilton, ${ }^{4}$ Caitlyn Timmings, ${ }^{5}$ \\ Yalnee Shantharam, ${ }^{6}$ Julia Moore, ${ }^{5}$ Andrea D Furlan, ${ }^{6,7}$ on behalf of the Safer \\ Prescribing of Opioids (SPO) Investigators
}

To cite: Leece P, Buchman DZ, Hamilton M, et al. Improving opioid safety practices in primary care: protocol for the development and evaluation of a multifaceted, theoryinformed pilot intervention for healthcare providers. BMJ Open 2017;7:e013244. doi:10.1136/ bmjopen-2016-013244

- Prepublication history and additional material is available. To view please visit the journal (http://dx.doi.org/10.1136/ 013244)

Received 22 August 2016 Revised 8 March 2017 Accepted 13 March 2017

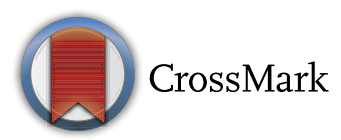

For numbered affiliations see end of article.

Correspondence to

Dr Andrea D Furlan; andrea.furlan@uhn.ca

\section{ABSTRACT}

Introduction In North America, drug overdose deaths are reaching unprecedented levels, largely driven by increasing prescription opioid-related deaths. Despite the development of several opioid guidelines, prescribing behaviours still contribute to poor patient outcomes and societal harm. Factors at the provider and system level may hinder or facilitate the application of evidence-based guidelines; interventions designed to address such factors are needed.

Methods and analysis Using implementation science and behaviour change theory, we have planned the development and evaluation of a comprehensive Opioid Self-Assessment Package, designed to increase adherence to the Canadian Opioid Guideline among family physicians. The intervention uses practical educational and self-assessment tools to provide prescribers with feedback on their current knowledge and practices, and resources to improve their practice. The evaluation approach uses a pretest and post-test design and includes both quantitative and qualitative methods at baseline and 6 months. We will recruit a purposive sample of approximately 10 family physicians in Ontario from diverse practice settings, who currently treat patients with long-term opioid therapy for chronic pain. Quantitative data will be analysed using basic descriptive statistics, and qualitative data will be analysed using the Framework Method.

Ethics and dissemination The University Health Network Research Ethics Board approved this study. Dissemination plan includes publications, conference presentations and brief stakeholder reports. This evidenceinformed, theory-driven intervention has implications for national application of opioid quality improvement tools in primary care settings. We are engaging experts and end users in advisory and stakeholder roles throughout our project to increase its national relevance, application and sustainability. The performance measures could be used as the basis for health system quality improvement indicators to monitor opioid prescribing. Additionally, the methods and approach used in this study could be adapted for other opioid guidelines, or applied to other areas of preventive healthcare and clinical guideline implementation processes.
Strengths and limitations of this study:

- The intervention development used a systematic process of mapping potential facilitators and barriers for opioid guideline adherence to a behaviour change framework to select and tailor appropriate implementation strategies.

- The evaluation approach uses a pretest and post-test design and includes both quantitative and qualitative data collection, allowing the assessment of changes in knowledge, performance and attitudes over time.

- Limitations of this study include the small number of participants in the initial pilot study and the resource constraints preventing inclusion of participants from more diverse jurisdictions and practice settings.

- The project scope does not allow us to gain insights from physicians who refuse to prescribe opioids and physicians who do not feel comfortable or have the time to participate in all aspects of the project.

- Our project also does not target prescribers who have been identified by the regulatory college as requiring remediation.

\section{INTRODUCTION}

The United States and Canada are ranked first and second globally for the highest consumption of prescription opioids per capita, ${ }^{1}$ and drug overdose deaths are reaching record levels. ${ }^{2-4}$ Unsafe opioid prescribing is viewed as a major contributor to this problem, including prescribing high doses and coprescribing with benzodiazepines. ${ }^{4-6}$

Interventions to improve opioid prescribing have been introduced, such as prescription drug monitoring programmes and clinical practice guidelines, but there is limited information on their effectiveness or the process by which they are implemented. ${ }^{7-11}$ Interventions with demonstrated effectiveness for changing medication prescribing behaviours 
include audit and feedback, computer decision support systems and multifaceted interventions. ${ }^{12}$ In addition, there is some literature to describe quality improvement processes using opioid prescribing indicators. ${ }^{1314}$

Our ongoing research is designed to address gaps in provider knowledge and practice in opioid prescribing for chronic pain compared with guidelines. We used a systematic approach rooted in behaviour change theory $^{1516}$ to select and tailor evidence-informed implementation strategies to support uptake of the Canadian Opioid Guideline. Our resulting multifaceted intervention will undergo a mixed-methods evaluation with family physicians, as the highest proportion (approximately $50 \%$ ) of total opioid prescribing occurs among general practitioners. ${ }^{17} 18$ The evaluative component will involve assessing the implementation strategies using a systematic mapping process and further tailoring the strategies as needed to ensure they are appropriately targeting the underlying barriers and facilitators to provider guideline use.

The primary objective of our research is to develop and evaluate an educational and quality improvement package with potential to improve Canadian family physicians' knowledge and performance in safer prescribing of opioids using the Canadian Guideline for Safe and Effective Use of Opioids for Non-Cancer Pain (herein referred to as the 'Canadian Opioid Guideline'). ${ }^{19}$ Our secondary objective is to assess changes in physician knowledge and practices before and after completing the Opioid Self-Assessment Package. Through this research, we will explore the barriers and facilitators to using the Canadian Opioid Guideline and the project tools, and use this information to make modifications to both the implementation strategies and the intervention components as required. The long-term goals of our research programme are to increase opioid prescriber adherence to the Canadian
Opioid Guideline and to decrease opioid-related adverse events among patients.

\section{METHODS AND ANALYSIS \\ Team and resources}

Our research is led by an interdisciplinary team with expertise in primary care, pain medicine, addiction medicine, medication safety, pharmacy, bioethics, public health, clinical epidemiology and implementation science. This project was one of the six awarded competitive peer-reviewed fundings from Health Canada to focus on prescriber education and monitoring of prescription drugs.

\section{Design}

We have planned the development of a pilot intervention and a mixed-methods evaluation of processes and outcomes(figure 1). Our project includes three phases:

1. completing the development of the Opioid SelfAssessment Package

2. pilot implementation and evaluation of the package

3. revision of the intervention and preparation for scaling up the package

The evaluation approach uses a pretest and post-test design and includes both quantitative and qualitative data collection, including opioid knowledge, medication safety processes, prescribing practices, and barriers and facilitators to guideline adherence (figure 2). This design allows us to track changes in knowledge, performance and attitudes over time.

\section{Setting}

This research is conducted in the context of the Canadian healthcare system, within a general primary care setting in the province of Ontario. In Canada, an estimated 20\% of the general population experiences chronic pain. ${ }^{20}$

Figure 1 Simplified logic model. 


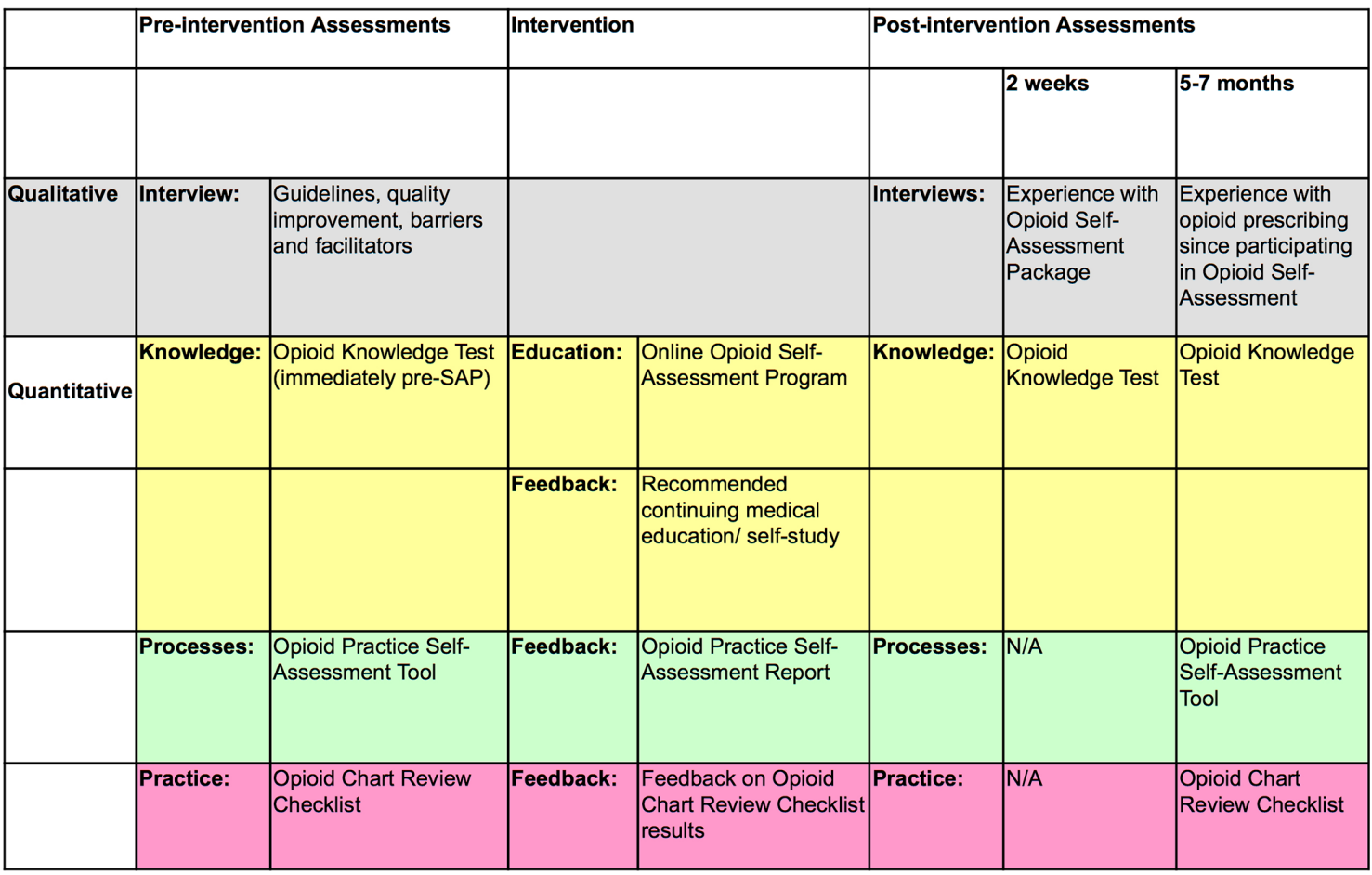

Figure 2 Project design. SAP, Self-Assessment Program.

Over the past two decades, opioid prescribing increased dramatically in Canada, including Ontario, and continues to rise. ${ }^{21}$ The Canadian Opioid Guideline was published in $2010,{ }^{19}$ and several implementation support tools have been developed to assist providers with using the guideline. ${ }^{22} 23$

\section{Participant eligibility and recruitment}

We will recruit a purposive sample of approximately 10 family physicians in Ontario, who currently treat patients with long-term opioid therapy for chronic pain. Participants will be contacted through our investigators' professional networks, snowball sampling techniques through enrolled participants and selected invitations using the College of Physicians and Surgeons of Ontario (CPSO) public physician register. We aim to have representation from diverse practice settings (eg, academic/ community, urban/suburban/rural and individual/ team). For feasibility of this initial pilot phase, we will involve physicians whose practice location is within a 2-hour travel distance from our study coordinating office in Toronto. We will exclude physicians with a focused practice in chronic pain or addiction, or physicians involved in the peer-review assessment process for the CPSO.

\section{Intervention}

Our intervention is multifaceted, informed by evidence and rooted in behaviour change theory. This approach is consistent with current implementation science literature suggesting that implementation strategies designed to tap into multiple domains of behaviour are more effective at producing meaningful behaviour change results. ${ }^{24}$
We used a systematic process of mapping potential facilitators and barriers for provider-level guideline adherence to a behaviour change framework. We used this analysis to select appropriate implementation strategies linked through behaviour change theory. This was completed using three independent raters and standardised worksheets. The specific behaviour change theory and framework we used were the COM-B theory and the Theoretical Domains Framework (TDF). ${ }^{15} 16$ The COM-B theory describes three basic conditions for behaviour, consisting of capability, opportunity and motivation. The TDF integrates 33 theories of behaviour change and identifies 14 domains of behaviour change that can be used in implementation and behaviour change research. The results of the mapping process will be further analysed to identify coverage and gaps in the implementation strategies selected to address each of the relevant behaviour change domains. On the basis of this analysis, we will identify areas that are currently addressed by the opioid intervention as well as potential areas to modify the pilot intervention. Additional details, including the results, of the mapping process will be published separately.

Next we drafted four products based on the Canadian Opioid Guideline and existing tools used elsewhere to comprise what we call the Opioid Self-Assessment Package. This package includes multiple components covering a broad range of knowledge and behaviours related to opioid prescribing. An initial assessment determines the need for further learning provided by an interactive online learning component. Beyond the theoretical knowledge gained and evaluated through 


\begin{tabular}{|c|c|c|c|c|c|c|c|}
\hline Products & Pre-Project & \multicolumn{5}{|c|}{${ }^{* *}$ Current Project Scope ${ }^{* *}$} & Post-Project \\
\hline \multirow{2}{*}{$\begin{array}{l}\text { 1. Opioid } \\
\text { Knowledge } \\
\text { Test }\end{array}$} & $\begin{array}{l}\text { Development: draft } \\
\text { questions }\end{array}$ & \multicolumn{2}{|c|}{$\begin{array}{l}\text { Validation: } \\
\text { content validity }\end{array}$} & \multicolumn{2}{|c|}{$\begin{array}{l}\text { Revision based on } \\
\text { expert participation }\end{array}$} & Pilot testing & Validation: construct validity \\
\hline & Validity: face validity & \multicolumn{5}{|c|}{$\begin{array}{l}\text { Expert consensus regarding the essential knowledge } \\
\text { and skills for examination, based on current guidelines } \\
\text { - Expert participation in exam revision to ensure content } \\
\text { validity } \\
\text { - Initial testing of questions with family physicians } \\
\text { participating in online Opioid SAP }\end{array}$} & $\begin{array}{l}\text { - Administration of exam questions to } \\
\text { groups with expected basic, } \\
\text { intermediate, and expert knowledge } \\
\text { - Rasch analysis for accuracy and } \\
\text { precision of exam questions }\end{array}$ \\
\hline \multirow[t]{2}{*}{$\begin{array}{l}\text { 2. Online } \\
\text { Opioid Self- } \\
\text { Assessment } \\
\text { Program } \\
\text { (SAP) }\end{array}$} & $\begin{array}{l}\text { (In-person Opioid SAP } \\
\text { content fully developed and } \\
\text { accredited) }\end{array}$ & $\begin{array}{l}\text { Revision } \\
\text { with web } \\
\text { developer }\end{array}$ & & $\begin{array}{l}\text { ot testing } \\
\text { d } \\
\text { aluation }\end{array}$ & $\begin{array}{l}\text { Revision } \\
\text { based on } \\
\text { pilot } \\
\text { testing } \\
\text { and } \\
\text { evaluation }\end{array}$ & $\begin{array}{l}\text { Additional } \\
\text { testing and } \\
\text { evaluation }\end{array}$ & $\begin{array}{l}\text { Revision based on additional testing } \\
\text { and evaluation }\end{array}$ \\
\hline & $\begin{array}{l}\text { Development: draft adapted } \\
\text { version for online format }\end{array}$ & \multicolumn{5}{|c|}{$\begin{array}{l}\text { In-depth pilot with } \sim 10 \text { prescribers participating in full } \\
\text { educational and quality improvement project } \\
\text { - Promotion of revised online Opioid SAP to broader } \\
\text { family medicine audience across Canada }\end{array}$} & $\begin{array}{l}\text { Scale-up promotion and knowledge } \\
\text { exchange activities, and monitor uptake }\end{array}$ \\
\hline \multirow{2}{*}{$\begin{array}{l}\text { 3. Opioid } \\
\text { Practice } \\
\text { Self- } \\
\text { Assessment } \\
\text { Tool }\end{array}$} & Development: draft tool & \multirow{2}{*}{$\begin{array}{l}\text { Validation: } \\
\text { expert } \\
\text { review for } \\
\text { face and } \\
\text { content } \\
\text { validity }\end{array}$} & \multirow{2}{*}{\multicolumn{2}{|c|}{$\begin{array}{l}\text { Revision } \\
\text { based on } \\
\text { expert } \\
\text { participation, } \\
\text { Modification } \\
\text { for web-form }\end{array}$}} & \multirow[t]{2}{*}{$\begin{array}{l}\text { Pilot } \\
\text { testing } \\
\text { and } \\
\text { evaluation }\end{array}$} & \multirow[t]{2}{*}{$\begin{array}{l}\text { Revision based } \\
\text { on pilot testing } \\
\text { and evaluation }\end{array}$} & $\begin{array}{l}\text { Further development of Opioid Practice } \\
\text { Self-Assessment Program in } \\
\text { collaboration with Institute for Safe } \\
\text { Medication Practices }\end{array}$ \\
\hline & & & & & & & Scale-up promotion, monitor uptake \\
\hline \multirow{2}{*}{$\begin{array}{l}\text { 4. Opioid } \\
\text { Chart } \\
\text { Review } \\
\text { Checklist }\end{array}$} & \multirow[t]{2}{*}{ Development: draft checklist } & \multirow{2}{*}{$\begin{array}{l}\text { Validation: } \\
\text { expert } \\
\text { review for } \\
\text { face and } \\
\text { content } \\
\text { validity }\end{array}$} & \multirow{2}{*}{\multicolumn{2}{|c|}{$\begin{array}{l}\text { Revision } \\
\text { based on } \\
\text { expert } \\
\text { participation, } \\
\text { Modification } \\
\text { for web-form }\end{array}$}} & \multirow{2}{*}{$\begin{array}{l}\text { Pilot } \\
\text { testing } \\
\text { and } \\
\text { evaluation }\end{array}$} & \multirow[t]{2}{*}{$\begin{array}{l}\text { Revision based } \\
\text { on pilot testing } \\
\text { and evaluation }\end{array}$} & $\begin{array}{l}\text { Further development of Opioid Chart } \\
\text { Review Checklist in collaboration with } \\
\text { partners }\end{array}$ \\
\hline & & & & & & & $\begin{array}{l}\text { Adaptation for regular EMR reporting } \\
\text { and ongoing quality improvement }\end{array}$ \\
\hline
\end{tabular}

Figure 3 Project product map. SAP, Self-Assessment Program.

these phases, other components of the package assess the implementation and practical application of this knowledge. Self-appraisal of actual practice habits and processes can identify aspects of opioid management where theoretical knowledge and practical application conflict. A chart review further provides even more in-depth evaluation of opioid-related prescribing and management behaviours against knowledge or accepted standards. In sum, the package incorporates online baseline knowledge assessment, a self-directed learning component incorporating multiple learning methods (online didactic, guideline review, video learning, practice questions and case examples), a knowledge examination, an assessment of a participant's own practice activities and routines and individual chart reviews. The development, revision and validation processes for these products are outlined in figure 3. The Opioid Self-Assessment Package includes:

Part 1-Online Opioid Self-Assessment Program (SAP) (online supplementary file 1): This accredited 3-hour online programme is adapted from an in-person workshop developed by one of our authors (AF) and other experts. The programme uses knowledge assessment to provide physicians with feedback about their opioid-related knowledge base, identify gaps in knowledge and areas for improvement and create individualised learning plans.

Part 2-Opioid Knowledge Test: Examination questions were developed with the guidance of an expert in creating examination questions and are integrated within the SAP. At the end of the SAP, participants complete a final knowledge test to identify areas for continued learning. The content of the online SAP includes five main sections: (1) deciding to initiate opioid therapy, (2) conducting an opioid trial, (3) monitoring long-term opioid therapy (LTOP), (4) treating specific populations with LTOP and (5) managing opioid misuse and addiction.

Part 3-Opioid Practice Self-Assessment Tool (online supplementary file 2): This component is adapted from other medication safety tools used by the Institute for Safe Medication Practices Canada. ${ }^{25-27}$ Our opioid practice self-assessment questionnaire takes approximately 2 hours to complete online and includes 70 items across seven core characteristics that influence the safety of opioid use. The prescriber evaluates the level of implementation of each item on a 5-point scale from 'No activity to implement' to 'Fully implemented throughout'.

Part 4-Opioid Chart Review Checklist (online supplementary file 3): This checklist will serve as a method of audit and feedback to opioid prescribers on their clinical performance. It is adapted from the practice review assessment form that is used by CPSO with methadone prescribers. ${ }^{28}$ An independent assessor with our project will review the charts, summarise findings and provide feedback to prescribers. The chart review will extract information on pain diagnoses and assessment, risk assessment, patient education, use of treatment agreements and use of urine drug screening tests, as well as the treatment plan and monitoring (including use of opioid, non-opioid and non-pharmacological interventions).

Finally, we analysed the components of the initial Opioid Self-Assessment Package for coverage and gaps in addressing each relevant behaviour change domain. On 
the basis of this analysis, we refined the intervention to address gaps, using evidence-based implementation strategies from the Rx for Change Database available through the Canadian Agency for Drugs and Technologies in Health. ${ }^{29} 30$

\section{Validity}

The validity of the tools in the Opioid Self-Assessment Package will undergo extensive review and revision among our investigators, prior to conducting the evaluation with family physicians. We will review them for clarity, appropriateness, face and content validity. These will be assessed based on the content of the Canadian Opioid Guideline and the various perspectives of our investigators across areas of expertise, particularly in family medicine, pain medicine, addiction medicine and pharmacy. The scope of the current project does not include validation among groups that could demonstrate an expected gradient of performance or against patient outcomes.

\section{Measurement}

The short-term outcomes of our project include developmental, formative and summative elements. Our formative project outcomes include establishing the Opioid Self-Assessment Package tools as well as understanding physician experiences with their use. Summative project outcomes include improving knowledge and adherence to the Canadian Opioid Guideline in practice. For further development of the project, we will gain insight into the facilitators and barriers for opioid prescribers to adhere to current guidelines.

Data sources for each of these outcomes will include:

1. physician demographics from the CPSO public register

2. online practice profile questionnaire (including prevalence of patients using long-term opioids)

3. Online Opioid SAP (Parts 1 and 2)

4. Opioid Practice Self-Assessment Tool (Part 3)

5. Opioid Chart Review Checklist (Part 4)

6. semistructured qualitative interviews.

\section{Procedures}

A summary of study procedures are outlined in table 1 . Data collection generally takes place in two phases: phase I consists of a baseline qualitative interview,

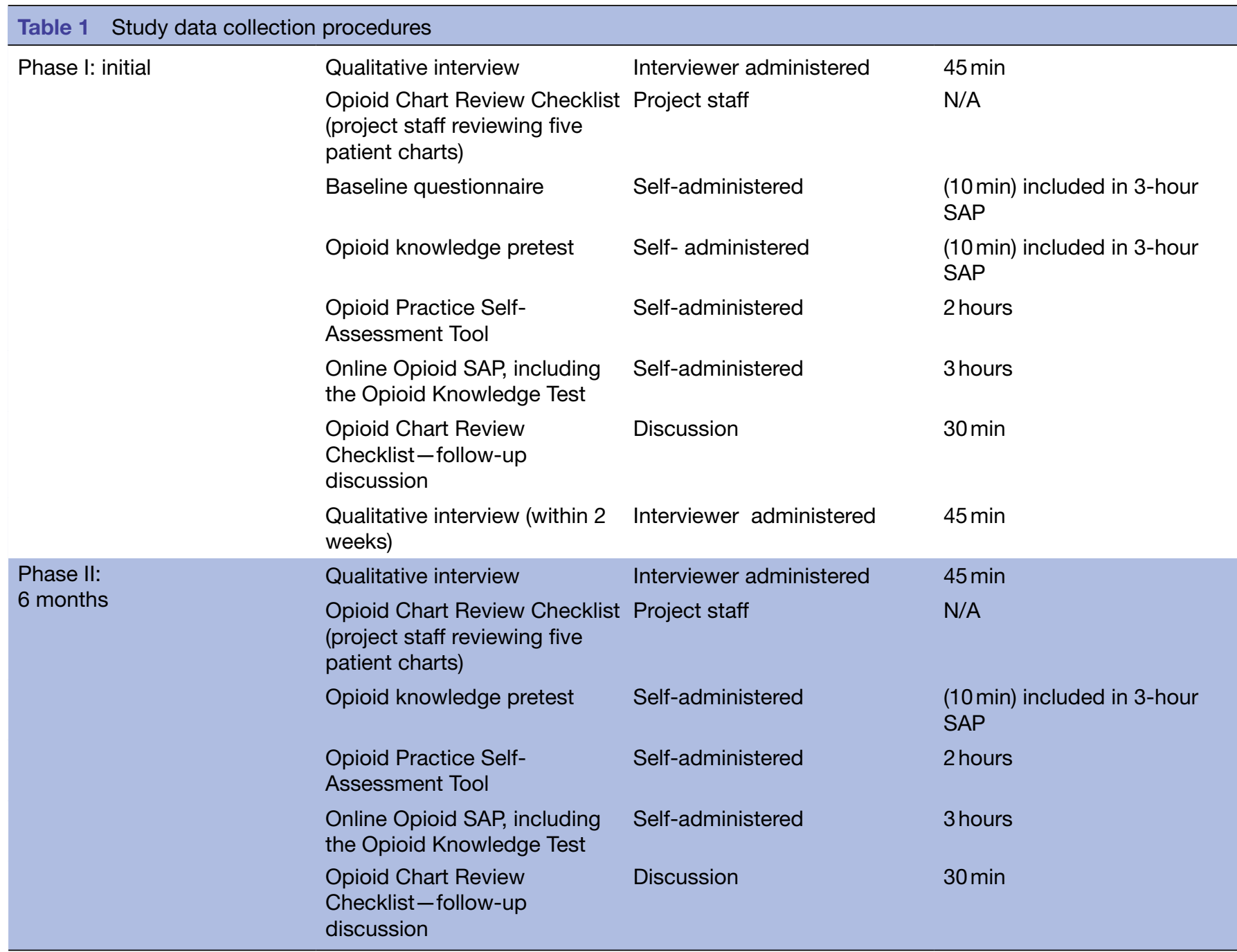


completing all study tools and a second qualitative interview. Phase II occurs approximately 6 months later, with a final qualitative interview and completing the study tools a second time to compare findings with baseline.

\section{Opioid Self-Assessment Package: Part 4-Opioid Chart Review Checklist}

Ten charts per participating physician will be reviewed by research staff using the Chart Review Checklist: five prior to completing the online SAP and five after approximately $5-7$ months. The participant will identify the five most recent patients initiated on opioid therapy for chronic pain who consent to the chart review. Data will be collected in duplicate by two reviewers until acceptable agreement is achieved, and disagreements will be mediated by one of the project investigators. We chose to proceed with manual review due to the present limitations of query searches in electronic medical records (EMRs) to identify patients using chronic opioid treatment, calculated daily doses and evaluate the adherence to guidelines for other aspects, including patient assessment, education and monitoring.

\section{Opioid Self-Assessment Package: Part 3—0pioid Practice Self- Assessment Tool}

The practice self-assessment form will be completed by each physician prior to completing the online SAP, and again 5-7 months later. This form will be available as a secure, web-based fillable form on the same website as the Online Opioid SAP.

\section{Opioid Self-Assessment Package: Part 2-Opioid Knowledge Test} and Online SAP Evaluation Questionnaire

The Opioid Knowledge Test will be completed by each participant prior to completing the online SAP, again immediately on completion of the online programme. Pretest and post-tests will be repeated within 5-7 months. An evaluation questionnaire will be completed at the end of the online SAP.

\section{Semistructured qualitative interviews}

Participants will be invited to participate in three $45 \mathrm{~min}$ semistructured qualitative interviews (baseline, within 2 weeks postintervention and 5-7 months postintervention) using standardised interview guides developed a priori. Interviews will be conducted in person when feasible or otherwise by telephone, and all interviews will be audio recorded with permission. The first interview will focus on facilitators and barriers to adherence to the Canadian Opioid Guideline, attitudes towards using quality improvement processes in clinical practice and clinical experiences relevant to the research objectives. The second interview will focus on physicians' experience with participating in the Opioid Self-Assessment Package. The third interview will focus on physicians' experience with opioid prescribing since participating in the Opioid Self-Assessment Package.

\section{Study retention}

To increase participant retention, we will maintain regular communication with participants to ensure ease of scheduling as well as provide reminders and updates on study progress. As an incentive to complete the full study, we have weighted study compensation towards completion of follow-up data collection (ie, 30\% compensation on completion of phase I and 70\% compensation on completion of phase II).

\section{Analysis}

\section{Quantitative data analysis}

To analyse the quantitative data from the Physician Practice Questionnaire, Online SAP (including knowledge test and evaluation questionnaire), Chart Review Checklist and Practice Self-Assessment Tool, we will be using basic descriptive statistics-frequencies, sums, means, medians, cross tabulations, $\chi^{2}$ and t-tests-in a database using PASW Statistics 18 (PASW Statistics for Windows, V.18.0., 2009).

\section{Qualitative data analysis}

Semistructured interviews will be transcribed verbatim, de-identified and analysed by two independent analysts using the NVIVO V.10 software. Full transcription of data will be analysed systematically using a qualitative content analysis approach that applies the Framework Method for analysis. ${ }^{31}$ Methods to address rigour will include using multiple coders in data analysis, and a technique called member checking, in which we may request clarification from participants on inconsistencies and ambiguities in the data. ${ }^{32}$

\section{ETHICS AND DISSEMINATION}

This study has been approved by the University Health Network Research Ethics Board and local Research Ethics Boards at recruitment sites as required. The study procedures do not involve direct contact with patients. We will provide feedback to physicians on their prescribing according to the Canadian Opioid Guideline. Physicians will use their own professional judgement to make any clinical changes based on this feedback. If we become aware of any serious differences in prescribing compared with guidelines, this will be included in their feedback with an opportunity for discussion with our project team. Our team will not share these individual findings with the physicians' affiliated institutions or regulatory college. There is a foreseeable possibility that information we learn would require mandatory reporting to the CPSO, as outlined in the CPSO Mandatory and Permissive Reporting Policy. Any issues involving reporting requirements will follow the CPSO policy, and we will review these issues with the Research Ethics Board.

The Opioid Self-Assessment Package has the potential to improve medication safety practices in primary care opioid prescribing and adherence to current opioid guidelines. This intervention connects evidence-based clinical guidelines and evidence-based implementation strategies 
using behaviour change theory. Experts in implementation science (CT and JM) provide implementation coaching services for our project. This includes support in the application of the Knowledge to Action process model,${ }^{33}$ use of behaviour change frameworks and theory, and selection and tailoring of implementation strategies to infuse implementation science principles and theory throughout the project stages. Using an integrated knowledge translation strategy, ${ }^{34}$ we seek to engage a diverse range of experts and end users in advisory and stakeholder roles throughout our project to increase its national relevance, application and sustainability. To ensure the sustainability of the project tools, we will engage one or more partners to host the project resources on an open electronic platform long term, and plan mechanisms for updating our project tools over time. The end-of-grant knowledge translation strategy also includes publishing several articles in peer-reviewed journals, presenting at academic conferences and providing summary reports to stakeholder organisations.

Our project fills several major gaps in current research and practice. The first is a gap in intervention research to support prescribers to improve both knowledge and behaviours in accordance with opioid guidelines. This project incorporates education and assessments directed towards both of these aspects, and results may identify and suggest methods of addressing knowledge-practice gaps. The second gap concerns the development of indicators for ongoing quality improvement in opioid prescribing; only limited work is published in this area. ${ }^{14}$ The Opioid Chart Review Checklist domains will be assessed for feasibility, acceptability and importance for ongoing monitoring of opioid prescribing. The third gap is identifying and describing the facilitators and barriers to adhering to opioid guidelines. Although some literature is informative for this, few studies contribute to specific knowledge of the dynamics related to opioid guideline adherence. ${ }^{35-39}$ In these ways our research is novel and will contribute to advancing the implementation of safer opioid prescribing practices and quality monitoring processes.

Limitations of this study include the small number of participants in the initial pilot study and the resource constraints preventing inclusion of participants from more diverse jurisdictions and practice settings. Our purposive sampling strategy and pre-post evaluation design were intended to support mainly qualitative findings and some hypothesis-generating quantitative results. However, this design limits the generalisability of our findings. In addition, the project scope does not allow us to gain insights from physicians who refuse to prescribe opioids and physicians who do not feel comfortable or have the time to participate in all aspects of the project. Our project also does not target prescribers who have been identified by the CPSO as requiring remediation. However, our study will advance the current evidence on facilitators and barriers to adherence to opioid prescribing guidelines in primary care and the introduction of provider-level educational and quality improvement tools for opioid prescribing using rigorous qualitative and evaluation methods.

The results of this study will be used to revise the educational module, quality improvement tools and implementation strategies. The project networks and tools will also be used as a basis for additional work, including development and validation of opioid prescribing quality indicators for EMR and administrative databases, understanding patient and family perspectives on opioid safety and longitudinal research on the impact of adherence to clinical guidelines on patient safety outcomes. The project team is committed to seeking additional funding from multiple non-industry sources to pursue these next steps. This work aligns with the Canadian strategy on reducing the harms of prescription drugs and has potential for application at the national level. ${ }^{40}$ In addition, the methods and approach used in this study could be adapted for other opioid guidelines and studied in other areas of preventive healthcare and clinical guideline implementation processes, so that other groups could replicate and learn from this process.

\section{PROJECT STATUS}

This project began recruitment in February 2016, and we expect to complete data collection in December 2016 and analysis by April 2017.

\section{Author affiliations}

${ }^{1}$ Public Health Ontario, Toronto, Ontario, Canada

${ }^{2}$ University Health Network, Toronto, Ontario, Canada

${ }^{3}$ University of Toronto Joint Centre for Bioethics, Toronto, Ontario, Canada

${ }^{4}$ Institute for Safe Medication Practices Canada, Toronto, Ontario, Canada

${ }^{5}$ Knowledge Translation Program, Li Ka Shing Knowledge Institute, St. Michael's

Hospital, Toronto, Ontario, Canada

${ }^{6}$ Toronto Rehabilitation Institute, University Health Network, Toronto, Ontario, Canada

${ }^{7}$ Department of Medicine, University of Toronto, Toronto, Ontario, Canada

Acknowledgements We acknowledge the contribution of the full Safer Prescribing of Opioids (SP0) Team to this project. Investigators: Dr Daniel Z. Buchman, Dr Andrea Furlan, Dr Michael Hamilton, Dr Meldon Kahan, Dr Pamela Leece, Dr Nav Persaud, Dr Sheryl Spithoff, Dr Beth Sproule, and Dr Anita Srivastava. Project administration: Ms Yalnee Shantharam, Ms Gina Marinakos. Knowledge Translation Consultation: Dr Sharon Straus, Dr Julia Moore, Ms Caitlyn Timmings and Dr Nadia Bashir.

Collaborators Dr Meldon Kahan, Dr Nav Persaud, Dr Sheryl Spithoff, Dr Beth Sproule, Dr Anita Srivastava, Ms Gina Marinakos, Dr Sharon Straus, Dr Nadia Bashir.

Contributors All authors as well as the additional members of our investigator team were involved in the concept and design of the study. All authors as well as the additional members of our investigator team were involved in recruitment. PL and YS are involved in data collection. PL drafted the protocol manuscript. All authors were involved in manuscript revision and approval and agree to be accountable for all aspects of the work.

Funding This work has been funded by a grant from Health Canada.

Competing interests None declared.

Ethics approval University Health Network Research Ethics Board.

Provenance and peer review Not commissioned; externally peer reviewed.

Open Access This is an Open Access article distributed in accordance with the Creative Commons Attribution Non Commercial (CC BY-NC 4.0) license, which permits others to distribute, remix, adapt, build upon this work non-commercially, and license their derivative works on different terms, provided the original work 
is properly cited and the use is non-commercial.See:http://creativecommons.org/ licenses/by-nc/4.0/

(c) Article author(s) (or their employer(s) unless otherwise stated in the text of the article) 2017. All rights reserved. No commercial use is permitted unless otherwise expressly granted.

\section{REFERENCES}

1. International narcotics control board. Narcoticdrugs: estimated world requirements for 2015 (Statistics for 2013). 2015. https://www. incb.org/documents/Narcotic-Drugs/TechnicalPublications/2014/ Narcotic_Drugs_Report_2014.pdf (accessed 25 January 2016).

2. Rudd RA, Aleshire N, Zibbell JE, et al. Increases in drug and opioid overdose deaths--United States, 2000-2014. MMWR Morb Mortal Wkly Rep 2016;64:1378-82.

3. Jones CM, Mack KA, Paulozzi LJ, et al. Pharmaceutical overdose deaths, United States, 2010. Jama 2013;309:657-9.

4. Centers for Disease Control and Prevention (CDC). Vital signs: overdoses of prescription opioid pain relievers---United States, 1999--2008. MMWR Morb Mortal Wkly Rep 2011;60:1487-92.

5. Gomes T, Juurlink DN, Dhalla IA, et al. Trends in opioid use and dosing among socio-economically disadvantaged patients. Open Med 2011;5:e13-22.

6. Sullivan MD, Bauer AM, Fulton-Kehoe D, et al. Trends in opioid dosing among Washington state medicaid patients before and after opioid dosing guideline implementation. J Pain 2016;17:561-8.

7. Haegerich TM, Paulozzi LJ, Manns BJ, et al. What we know, and don't know, about the impact of state policy and systems-level interventions on prescription drug overdose. Drug Alcohol Depend 2014:145:34-47.

8. Morgan L, Weaver M, Sayeed Z, et al. The use of prescription monitoring programs to reduce opioid diversion and improve patient safety. J Pain Palliat Care Pharmacother 2013;27:4-9.

9. Green TC, Mann MR, Bowman SE, et al. How does use of a prescription monitoring program change medical practice? Pain Med 2012;13:1314-23.

10. Paulozzi LJ, Kilbourne EM, Desai HA. Prescription drug monitoring programs and death rates from drug overdose. Pain Med 2011;12:747-54

11. Nuckols TK, Anderson L, Popescu I, et al. Opioid prescribing: a systematic review and critical appraisal of guidelines for chronic pain. Ann Intern Med 2014;160:38-47.

12. Canadian Agency for Drugs and Technologies in Health. $R x$ for change:2013 http://www.cadth.ca/resources/rx-for-change (accessed 29 May 2013).

13. Perera R, Moriarty H. Prescription safety pilot project: report to the health quality and safety commission. $2013 \mathrm{http}: / / \mathrm{www}$.hqsc.govt. $\mathrm{nz} /$ assets/Other-Topics/QS-challenge-reports/A-prescription-safetypilot-project-Final-Report.pdf (accessed 05 August 2014).

14. Midboe AM, Lewis ET, Paik MC, et al. Measurement of adherence to clinical practice guidelines for opioid therapy for chronic pain. Trans/ Behav Med 2012;2:57-64.

15. Cane J, O'Connor D, Michie S. Validation of the theoretical domains framework for use in behaviour change and implementation research. Implement Sci 2012;7:37.

16. Michie S, van Stralen MM, West R. The behaviour change wheel: a new method for characterising and designing behaviour change interventions. Implement Sci 2011;6:42.

17. Chen JH, Humphreys $\mathrm{K}$, Shah $\mathrm{NH}$, et al. Distribution of opioids by different types of medicare prescribers. JAMA Intern Med 2016;176:259-61.

18. Levy B, Paulozzi L, Mack KA, et al. Trends in opioid AnalgesicPrescribing rates by specialty, U.S., 2007-2012. Am J Prev Med 2015;49:409-13.

19. Furlan AD, Reardon R, Weppler C. National Opioid Use Guideline Group. Opioids for chronic noncancer pain: a new canadian practice guideline. Cmaj 2010;182:923-30.
20. Schopflocher D, Taenzer P, Jovey R. The prevalence of chronic pain in Canada. Pain Res Manag 2011;16:445-50.

21. Ontario Drug Policy Research Network (ODPRN). Opioid prescribing and Opioid-Related hospital visits in Ontario (UPDATED FINAL REPORT march 2016). 2016. http://odprn.ca/wp-content/uploads/ 2016/03/FINAL-UPDATED_Opioid-Hosp-Report-_March-2016.pdf (accessed 09 May 2016).

22. Robertson A, Hitzig SL, Furlan AD. An evaluation of the performance of the opioid manager clinical tool in primary care: a qualitative study. J Opioid Manag 2014;10:187-99.

23. Furlan $A D$, Reardon $R$, Salach $L$. The opioid manager: a point-of-care tool to facilitate the use of the canadian opioid guideline. J Opioid Manag 2012;8:57-61.

24. Francke AL, Smit MC, de Veer AJ, et al. Factors influencing the implementation of clinical guidelines for health care professionals: a systematic meta-review. BMC Med Inform Decis Mak 2008;8:38.

25. Greenall J, U D, Lam R. An effective tool to enhance a culture of patient safety and assess the risks of medication use systems. Healthc Q 2005;8Spec No:53-8.

26. Johnson PE, Chambers CR, Vaida AJ, et al. International medication safety self assessment for oncology practice. J Oncol Pharm Pract 2011;17:303.

27. Institute for Safe Medication Practices Canada. Preliminary results from the international medication safety self assessment for oncology. 2013;13. http://ismp-canada.org/download/ safetyBulletins/2013/ISMPCSB2013-06_International_MSSA_ Oncology.pdf.

28. College of Physicians and Surgeons of Ontario. Methadone prescriber practice review patient assessment checklist . 2011 www.cpso.on.ca/uploadedFiles/policies/guidelines/facilties/ MethadonePrecriberPracticeReview.pdf (accessed 27 April 2016).

29. Canadian agency for drugs and technologies in health. Rx for change. 2010. http://www.cadth.ca/resources/rx-for-change (Accessed 29 May 2013).

30. Canadian agency for drugs and technologies in health (CADTH). Rx for change fact sheet. 2010. http://www.cadth.ca/media/pdf/2.20.0. 1-Rx_for_Change_FactSheet_e.pdf. (accessed 04 Jun 2014).

31. Gale NK, Heath G, Cameron E, et al. Using the framework method for the analysis of qualitative data in multi-disciplinary health research. BMC Med Res Methodol 2013;13:117.

32. Lincoln YS, Guba EG. Naturalistic inquiry. Newbury Park: Sage Publications, 1985.

33. Graham ID, Logan J, Harrison MB, et al. Lost in knowledge translation: time for a map? J Contin Educ Health Prof 2006;26:13-24.

34. Canadian Institutes of Health Research. Guide to knowledge translation planning at CIHR: Integrated and End-of-Grant Approaches. 2012 http://www.cihr-irsc.gc.ca/e/documents/kt_Im ktplan-en.pdf (accessed 13 May 2016).

35. Anderson D, Wang S, Zlateva I. Comprehensive assessment of chronic pain management in primary care: a first phase of a quality improvement initiative at a multisite community health center. Qual Prim Care 2012;20:421-33.

36. Barry DT, Irwin KS, Jones ES, et al. Opioids, chronic pain, and addiction in primary care. J Pain 2010;11:1442-50.

37. Jamison RN, Sheehan KA, Scanlan E, et al. Beliefs and attitudes about opioid prescribing and chronic pain management: survey of primary care providers. J Opioid Manag 2014;10:375-82.

38. Leverence RR, Williams RL, Potter M, et al. PRIME Net Clinicians. Chronic non-cancer pain: a Siren for primary care--a report from the PRImary care MultiEthnic network (PRIME net). J Am Board Fam Med 2011;24:551-61.

39. Porucznik CA, Johnson EM, Rolfs RT, et al. Opioid prescribing knowledge and practices: provider survey following promulgation of guidelines-Utah, 2011. J Opioid Manag 2013;9:217-24.

40. National advisory committee on prescription drug misuse. First do no harm: responding to Canada's prescription drug crisis. $2013 \mathrm{http}: / /$ www.ccsa.ca/2013CCSADocuments/Canada-Strategy-PrescriptionDrug-Misuse-Report-en.pdf (accessed 13 May 2013). 